\title{
Impact of solvents on the extraction and purification of vegetable dyes onto the efficiency for dye-sensitized solar cells
}

\author{
Javier Ramirez-Perez ${ }^{1,2^{*}}$, Calero Maria ${ }^{3}$ and Cristian P. Santacruz ${ }^{3}$
}

\begin{abstract}
Eight vegetable dyes extracted from flowers, fruits and leaves abundant in the wide biodiversity of the Andes region of South America were extracted with ethanol without purification to explore as vegetable photosensitizers in dye-sensitized solar cells (DSSCs). The absorbance spectra were measured by UV-visible spectroscopy and the photoelectrical performance of the DSSCs based on these dyes with a homemade solar simulator, constructed only for educational purposes under 1 sun of illumination. The open-circuit voltages $\left(V_{o c}\right)$ and the short-circuit photocurrent densities $\left(J_{\mathrm{sc}}\right)$ varied from 0.39 to $0.48 \mathrm{~V}$ and from 0.04 to $0.56 \mathrm{~mA} \mathrm{~cm}^{-2}$, and the power conversion efficiency (PCE) ranged from 0.01 to $0.18 \%$. Particularly, the highest $V_{\text {oc }}$ and PCE values of the DSSCs sensitized by the ethanol extracts of Mortiño fruit (Vaccinium floribundum) and Jamaica flowers (Hibiscus sabdariffa) without purification were presumably associated with anthocyanin, the most effective component present in both vegetable photosensitizers. Hence, various components of the ethanol extracts obtained from these two vegetable dyes were purified by liquid-liquid extraction using different organic solvents of different polarity, namely petroleum ether, chloroform, ethyl acetate, $n$-butanol, and distilled water. Ethyl acetate resulted as the most favorable solvent for purification of ethanol extracts from Mortiño fruit and Jamaica flowers to use as vegetable photosensitizers in DSSCs. The PCE of the DSSC fabricated with the dye extracted in ethyl acetate from Mortiño fruit achieved $0.33 \%$, with $V_{\text {oc }}$ of $0.520 \mathrm{~V}$ and $J_{\text {sc }}$ of $1.014 \mathrm{~mA} \mathrm{~cm}^{-2}$, whereas the corresponding values obtained from the dye extracted from Jamaica flowers reached $0.22 \%$ with $V_{\text {oc }}$ of $0.541 \mathrm{~V}$ and $J_{\text {sc }}$ of $0.678 \mathrm{~mA} \mathrm{~cm}^{-2}$. Thus, the purification of vegetable dyes used as photosensitizer impacts the photoelectrochemical performance of DSSCs.
\end{abstract}

Keywords: Vaccinium floribundum, Hibiscus sabdariffa, Natural dye sensitizers, Anthocyanin, Power conversion efficiency

\section{Background}

DSSCs, regarded as one of the most hopeful category of photovoltaic devices for the conversion of solar energy to electricity, have been widely investigated because of their high theoretical PCE, simple fabrication process, low cost, a great potential for large-scale applications (Cherepy et al. 1997; Vekariya et al. 2016). Generally, the major components of DSSCs are photo-electrodes, photosensitizers, electrolytes, and counter electrodes

\footnotetext{
*Correspondence: jramire7@kent.edu

${ }^{2}$ Department of Chemistry and Biochemistry, Kent State University at Stark, 6000 Frank Ave NW, North Canton, OH 22720, USA

Full list of author information is available at the end of the article
}

(Scheme 1). Among these four major components, photosensitizers categorically play an important role, as they are the origin of light harvesting in DSSCs (Vekariya et al. 2016). DSSCs reach a maximum PCE around $13 \%$ by using a porphyrin photosensitizer and graphene nanoplatelets (GNPs) as a counter electrode (CE) (Calogero et al. 2015; Salam et al. 2015). Metal organic dyes (ruthenium polypyridil complex) have been used as efficient photosensitizers for DSSCs. In laboratory scale, a PCE of $11.1 \%$ has already been achieved by exploring ruthenium (Ru-based complex dye) $\mathrm{N}-719$ attached to the $\mathrm{TiO}_{2}$ under 1 sun illumination (Calogero et al. 2015). However, the preparation routes for metal complexes are often based on multi-step reactions involving long, tedious and 


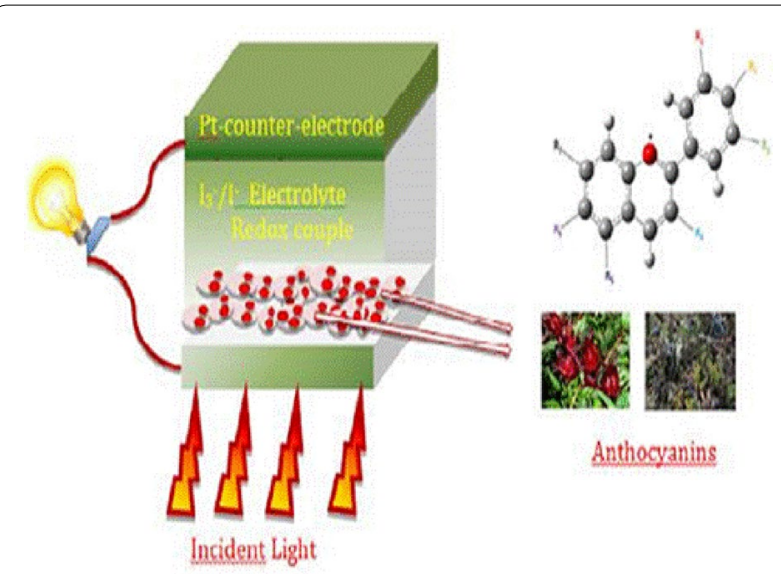

Scheme 1 Graphical abstract of dyes sensitized solar cells

expensive chromatographic purification procedure. Rubased complex dyes contain heavy metals; its large-scale application may cause the generation of large amount of synthetic wastes, which produces environmental pollution (Sunk Jung and Lee 2013; Abdou et al. 2013). Conversely, vegetable photosensitizer and their derivatives have emerged as an environmentally friendly alternative of DSSCs, since they are easily available and abundant in nature, easy to extract, non-toxic, and cost-effective. The treatments of vegetable dyes are simple, cheap, complete biodegradable, and do not produce hazardous wastes (Nayaran 2012). Therefore, a growing number of vegetable dyes have been extracted from fruits, flowers, leaves, algae, microorganism, etc., and extensively studied and tested as photosensitizers in DSSCs; these dyes include: anthocyanin, flavonoid, cyanine, betalian, chlorophyll, carotenoid, and tannin (Calogero et al. 2012; RamirezPerez and Solano 2013). In this study, eight vegetable dyes originally from the Andean sierra of Ecuador at elevations between 6000 and 13,000 ft have been selected for the preparation of photosensitizers of DSSCs namely, Mortiño fruits (Vaccinium floribundum) is native Andean highland shrub grows in the wild and cold weather and remains undomesticated and belongs to Ericaceae family. The fruit is edible and tasty known as blueberry of the Andes; since ancient times, it has been used as traditional medicine and colada morada, an Ecuadorian beverage made in the all saint's day (Coba et al. 2012). Mora fruits (Rubus glaucus) commonly known as Mora de Castilla or Andean Raspberry, belonging to the rose family, it is a species of blackberry, the fruit is ellipsoid compound drupe green when formed, becoming red when ripe, and then dark and bright purple, it is bittersweet, and suitable for beverages and pastries and confectionery (Idarraga-Piedrahita et al. 2011). Berenjena fruit (Solanum melongena) is the common name in South America, belongs to Solanaceae family a species of nightshade grown for its edible fruit, which is widely used in cooking (Sarli 1980). Tomate de arbol (Solanum betaceum) is grown at higher elevations of the Andes region including Ecuador; it is a small tree that belongs to the Solanaceae family, an egg-shaped edible fruit; it is also known as Tamarillo (Zuloaga et al. 2008). Jamaica flowers (Hibiscus sabdariffa) belong to Malvaceae family, the plants grow as shrub in freshly red flowers, and they are used as beverage daily (UPOV 2000). Ataco leaves (Amarantus quitenses) is a plant species with flowers belonging to the Amaranthaceae family; it is used by native people of Ecuador to treat epilepsy, as well as herbal medicinal beverage (Idarraga-Piedrahita et al. 2015). Rabano (Raphanus sativus) seems to have been one of the first European crops introduced to the Americas; it is an edible root vegetable of the Brassicaceae family; Rabanos are grown and consumed in the Andean region, being mostly eaten raw as a crunchy salad vegetable (Holgren and Holmgren 2005), and Achiote Bixa Orellana is a shrub originating from the tropical region of Andes; natives of Ecuador use the seeds to make red body paint and lipstick, as well as spice (Ranner et al. 1990).

The performance of DSSC using vegetable dyes extracted in different solvents has been studied, and the reported results show that the performance does depend on the solvent properties such as polarity, acidity, dye combination, and temperature (Lim et al. 2015; Warkkoyo 2011). The solubility of these vegetable dyes changes depending of the polarity of the extraction solvents, affecting the solubility and subsequently the adsorption behavior between the extracted dyes bonding onto $\mathrm{TiO}_{2}$ surface, consequently affecting the cell PCE (Wongcharee et al. 2007; Sreekala et al. 2012). Commonly, the polarity of solvents, aprotic and protic regularly used to extract and purified vegetable dyes can influence in terms of diffusion of dyes onto the $\mathrm{TiO}_{2}$ surface (Wongcharee et al. 2007). Consequently, solvents used to extract vegetable dyes must be carefully chosen to achieve high effectiveness in the extraction process. Lim et al. reported that using polar aprotic solvents as the extraction solvent more anthocyanin was extracted from Ixaora coccinea. However, when tested in DSSC, polar protic solvents exhibited better performances than the dyes extracted in polar aprotic solvents. Indeed, the DSSC assembled with a dye photosensitizer extracted in $70 \%$ ethanol achieved the highest PCE, $0.5 \%$; this was followed by the DSSC assembled with a dye photosensitizer extracted in acetone $(\mathrm{PCE}=0.3 \%)$, absolute ethanol $(\mathrm{PCE}=0.27 \%)$, dimethyl formamide ( $\mathrm{PCE}=0.17 \%)$, dimethyl sulfoxide $(\mathrm{PCE}=0.16 \%)$, and distilled water $(\mathrm{PCE}=0.09 \%)(\mathrm{Lim}$ et al. 2015). Zhou et al. assembled DSSCs sensitized with 
twenty different Chinese vegetable dyes extracted with ethanol among them; the DSSC sensitized by mangosteen pericarp achieved the highest PCE of $1.17 \%$. Furthermore, the ethanol extract obtained from magosteen pericarp was purified stepwise using different solvents and measured the PCEs of each extract. The PCEs of the DSSCs using the extracts of mangosteen pericarp purified with chloroform $(0.92 \%)$ and ethyl acetate $(1.12 \%)$ were higher than those of the extracts with $n$-butanol $(0.33 \%)$ and water $(0.3 \%)$. The authors concluded that the PCE of DSSC using ethanol as solvent is much lower than the sum of the PCEs of the DSSCs sensitized with extracts, suggesting that the mixed extract adsorbed on $\mathrm{TiO}_{2}$ does not show synergistic photosensitization compared with individual extracts (Zhou et al. 2011).

In this article, eight vegetable dyes were extracted from flowers, fruits and seeds, traditional Andean medicines, and beverages such as Mortiño, Mora, Berenjena and Tomate de arbol fruits; Jamaica and Ataco leaves, Rabano root vegetable, and Achiote seeds. To the best of our knowledge, Jamaica flowers and Mortiño fruit have not been evaluated previously as photosensitizers of DSSCs. These vegetable dyes were extracted with ethanol solvent at $\mathrm{pH} 1$ without purification; the extracting dyes were characterized by UV-Vis absorption spectra and the photoelectrochemical properties of the DSSCs using these extracts as photosensitizers. Thereafter, the two photosensitizers that reported the highest PCE of DSSCs were selected for further step-by-step purification using organic solvents of different polarity, namely petroleum ether, chloroform, ethyl acetate, $n$-butanol, and distilled water, and the photovoltaic properties of DSSCs sensitized by the purified products were investigated.

\section{Methods}

\section{Preparation of vegetable dye photosensitizers}

Eight vegetable dyes, namely Mortiño, Mora, Berenjena and Tomate de arbol, Jamaica, Ataco, Rabano, and Achiote seeds, were sampled and collected from the Andean region of Ecuador $\left(3.99^{\circ} \mathrm{S}, 79.2^{\circ} \mathrm{W}\right)$. Then samples were crushed into fine powder using a mortar. $10 \mathrm{~g}$ of each dye powdered was separately put in a $250-\mathrm{mL}$ Erlenmeyer containing $100 \mathrm{~mL}$ of absolute ethanol (Merk, Germany) adjusted at $\mathrm{pH} 1$. The $\mathrm{pH}$ was tuned with $\mathrm{HCl}$ $0.1 \mathrm{~N}$ or $\mathrm{NaOH} 0.1 \mathrm{~N}$, and followed the same extraction procedure, the Erlenmeyer was closed and covered with aluminum paper, to kept in the absence of sunlight and placed in a shaker at $50 \mathrm{rpm}$ for $24 \mathrm{~h}$ at room temperature. Then the solids were filtrated out, to acquire a pure vegetable dye solution, and were stored at $4{ }^{\circ} \mathrm{C}$ ready for use as photosensitizers. The synthetic dye di-tetrabutulammonium cis-bis(isothiocyanato)bis(2,2'-bipyridyl4,4'-dicarboxilato) ruthenium (II), namely N719, was prepared in ethanol and served as standard reference (Bethouex and Brown 1994; Georgescu et al. 2008). The effect of extracting solvent was studied by comparison of dyes extracted in solvents of different polarity index, petroleum ether, chloroform, $n$-butanol, ethyl acetate, ethanol and distilled water, through step-by-step liquidliquid extraction (Zhou et al. 2011).

\section{Preparation of photo-electrodes}

Fluorine-doped $\mathrm{SnO}_{2}$ (FTO) deposited on glass, sheet resistance $15 \Omega / \mathrm{sq}$ (Solaronix), $2.2 \mathrm{~mm}$ tick, area: $5 \mathrm{~cm} \times 5 \mathrm{~cm}$, was used both at the photo-anode, as support for the dye-sensitized oxide, and at the counter electrode (CE). FTO conductive glass plates were cleaned in a detergent solution using an ultrasonic bath for $15 \mathrm{~min}$, rinsed with abundant distilled water and isopropanol and dried at $70{ }^{\circ} \mathrm{C}$ for $30 \mathrm{~min}$. A thin film was coated using screen-printing technique (frame with SEFAR PET 1500, 77/195-55PW) on a spot area of $25 \mathrm{~mm}^{2}$ FTO glass plate and then dried for $7 \mathrm{~min}$. at $120^{\circ} \mathrm{C}$. This coating procedure was repeated to increase the thickness from one layer to five layers in order to form a thick layer of $\mathrm{TiO}_{2}$ film thickness of $8.78 \mu \mathrm{m}$ on the FTO glass plate. To prevent cracking during film drying, the plates coated with $\mathrm{TiO}_{2}$ once dried were gradually and sintered under airflow at $325{ }^{\circ} \mathrm{C}$ for $5 \mathrm{~min}, 375{ }^{\circ} \mathrm{C}$ for $5 \mathrm{~min}, 450{ }^{\circ} \mathrm{C}$ for $15 \mathrm{~min}$ and at $500{ }^{\circ} \mathrm{C}$ for $15 \mathrm{~min}$, at a heating rate of $4.8{ }^{\circ} \mathrm{C} / \mathrm{min}$, hence to improve the electronic contact between the $\mathrm{TiO}_{2}$ nanoparticles and to eliminate internal air bubbles and voids. Finally, it was cooled down to room temperature. The CE consisted in a glass sheet resistance $(15 \Omega / \mathrm{sq})$, where Pt was deposited chemically onto the FTO (Solaronix). This positive photo-cathode is a conductive glass plate (area: $4 \mathrm{~cm}^{2}$ ) on which a hole ( $2 \mathrm{~mm}$ diameter) was drilled. The perforated substrates were washed and cleaned with distilled water and ethanol in order to remove any residual of glass powder or organic contaminants (Chang and Lo 2010).

\section{Adsorption on $\mathrm{TiO}_{2}$ process}

The dye solutions of each dye were adsorbed by soaking the screen printed glasses (photo-anodes) for $24 \mathrm{~h}$, covered with aluminum paper to protect from light exposition at room temperature. The excess dye was removed by rinsing the photo-anodes with the same employed in the dye solution. Finally, these photo-anodes were dried and stored in a desiccator.

\section{DSSCs nano-fabrication}

The photo-anode and the photo-cathode were assembled into a sandwich-type arrangement and sealed (using an iron as thermopress) with a hot melt gasket made of the Surlyn ionomer (Ramirez-Perez and Solano 2013; 
Calogero et al. 2012). The electrolyte was prepared by dissolving the redox couple, $\mathrm{I}^{-} / \mathrm{I}_{3}^{-}\left(\mathrm{LiI} 0.7 \mathrm{M}\right.$ and $\mathrm{I}_{2}$ $0.05 \mathrm{M}$ ), in 3-methoxypropionitrile (MPN) solvent (Lim et al. 2015). A drop of electrolyte solution was put on the hole in the back of the photo-cathode. The electrolyte was introduced into the cell via backfilling under vacuum. The cell was placed in a small vacuum chamber to remove air inside. Exposing it again to ambient pressure causes the electrolyte to be driven into the cell. Finally, the hole was sealed using another Surlyn film and closing by a thin cover glass. An additive sealing with epoxydic resins was applied to avoid the leakage of solvent vapors out from the cell and insure a longer temporal stability of the device (Polo and Iha 2006; Calogero et al. 2012).

\section{Characterization and measurements}

The absorption spectra of the dye-extracted solutions and the dyes adsorbed on $\mathrm{TiO}_{2}$ nanoparticle film photoanodes were measured using UV-Vis Shimadzu 1800 spectrophotometer. The $\mathrm{TiO}_{2}$ film photo-anode was investigated by personal scanning electron microscopy (PSEM) eXpress ${ }^{\mathrm{TM}}$ from Aspex; the morphology and thickness of the $\mathrm{TiO}_{2}$ were characterized using an AFM Bruker Dimension Icon.

The current-voltage conversion responses of the assembled DSSCs were studied using a homemade solar simulator built for this project for educational purposes. The voltage and current of the DSSCs curves were recorded with a digital Keithley 236 multimeter (USA) under illumination $\left(100 \mathrm{~mW} \mathrm{~cm}^{-2}\right.$ ) provided by our homemade solar simulator connected to a PC and controlled by a Lab view program.

\section{Measurement of photoelectric conversion efficiency of DSSC}

The fill factor (FF), the open-circuit voltage $\left(V_{\mathrm{oc}}\right)$, the current density $\left(J_{\mathrm{sc}}\right)$ and the photoenergy, conversion efficiency $(\eta)$ were acquired as photoelectrochemical parameters. In particular, the FF was obtained by the following equation:

$$
\mathrm{FF}=\frac{I_{\max } \times V_{\max }}{I_{\mathrm{sc}} \times V_{\mathrm{oc}}}
$$

where $I_{\max }$ and $V_{\max }$ are the photocurrent and the photovoltage for maximum power output and $I_{\mathrm{sc}}$ is the short-circuit photocurrent. Furthermore, the power conversion efficiency (PCE) parameter was determined by the relation:

$$
\mathrm{PCE}=\frac{I_{\mathrm{sc}} \times V_{\mathrm{oc}} \times \mathrm{FF}}{P_{\mathrm{in}}}
$$

where $P_{\text {in }}$ denotes the energy of incident photon.

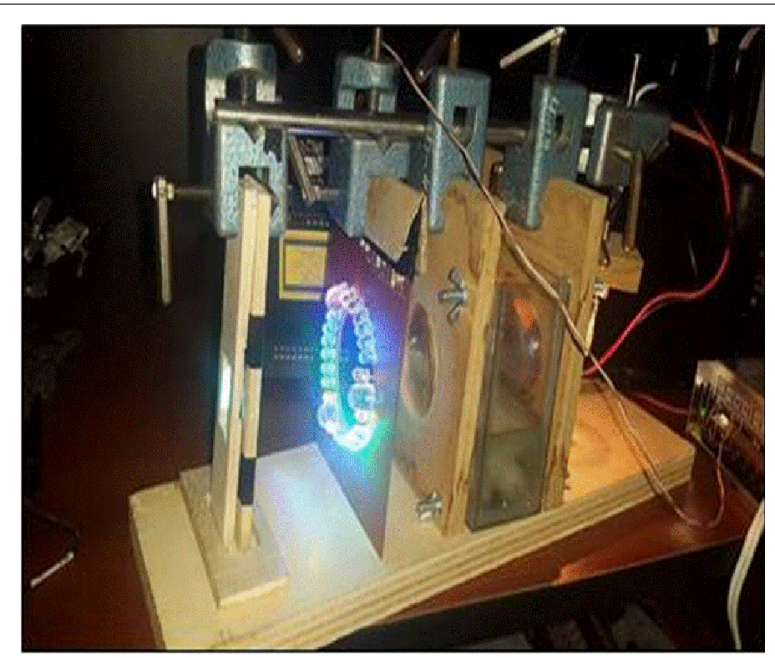

Fig. 1 Homemade solar simulator layout

\section{Statistics}

Error analysis of photoelectrochemical parameters of eight vegetable dyes based DSSCs was carried out to estimate the experimental errors that come out from open-circuit voltage $\left(V_{\mathrm{oc}}\right)$, short-circuit photocurrent densities $\left(J_{\text {sc }}\right)$, fill factor (FF) and efficiency $\eta(\%)$. The samples taken for each DSSC were carried out in triplicate $(n=3)$; the results were expressed as mean $\pm 95 \%$ confidence interval, i.e., $m \pm t s / \sqrt{ } n$, where $m$ is the mean of the $n$ values $(n=3), s$ is the estimated standard deviation, and $t$ is given by the Student-Fisher distribution for $95 \%$ of confidence interval and a degree of freedom of $n-1$ (Bethouex and Brown 1994).

\section{Results and discussion}

\section{Homemade solar simulator for dye-sensitized solar cell} testing

The construction of the solar simulator was based on the descriptions previously reported by Georgescu et al. (2008), Kohraku and Kurokawa (2003) for research and teaching purpose. A regular halogen $55 \mathrm{~W}-12 \mathrm{~V}$ headlight tungsten halogen lamp was used, which is an incandescent lamp with a tungsten filament sealed into a compact transparent envelope filled with an inert gas and a small amount of halogen such as iodine or bromine (Georgescu et al. 2008). The optical system is based on two-lens one biconvex glass $3.4 \mathrm{~cm}$ radius and the other meniscus convex $4.4 \mathrm{~cm}$ divided by a water column placed in spectroscopic glass into the path of the halogen lamp light beam. Finally, for improving more the spectrum performance, twenty-eight different colors LEDs lights are arranged in circle focus in an area of $2.5 \mathrm{~cm}^{2}$. Figure 1 presents the solar simulator mounted in a wood structure and metallic frame adjusted by flange nuts. All 


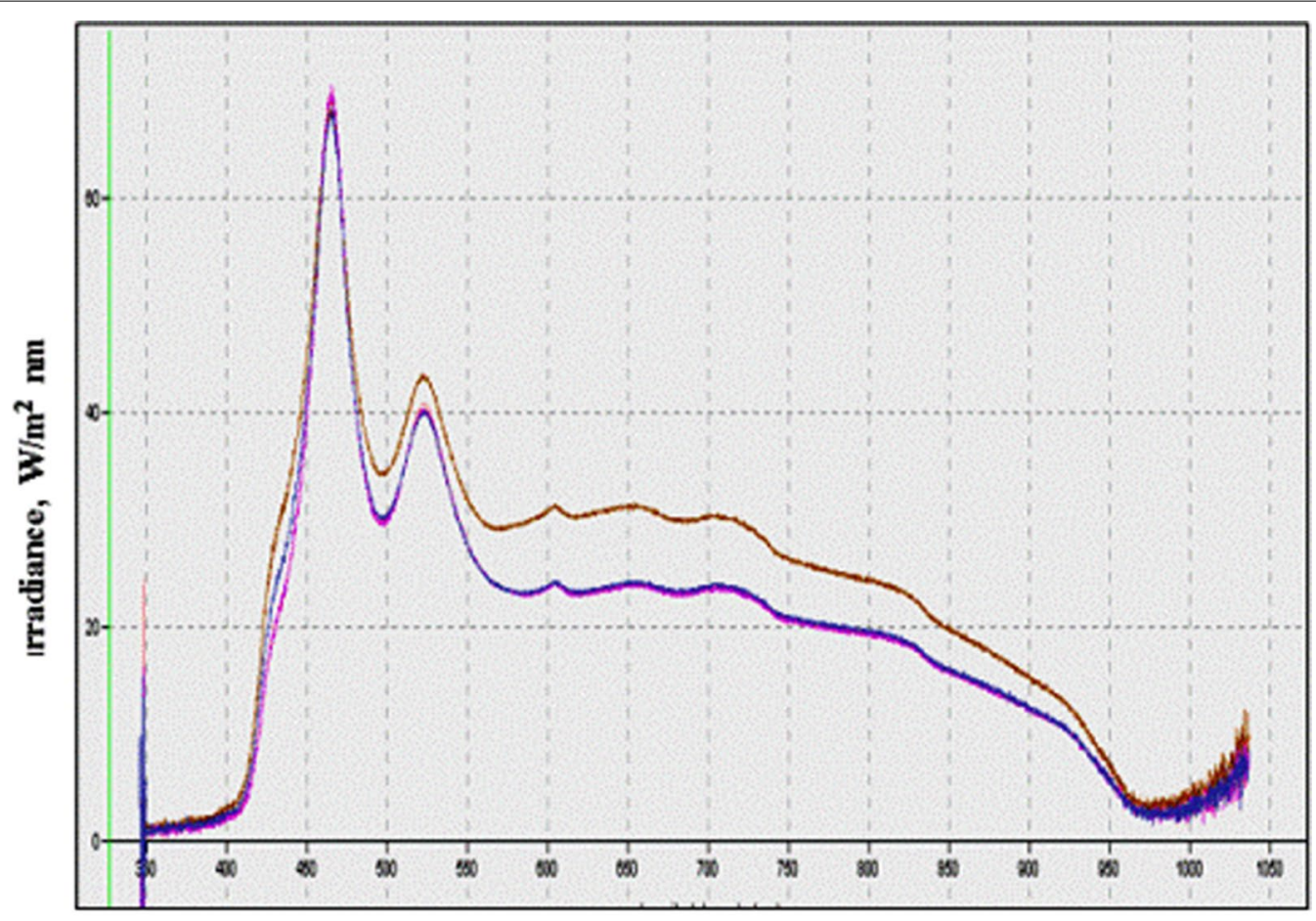

Wavelength, nm

Fig. 2 Complete simulator spectrum (red), compared with the solar spectrum in Quito, Ecuador (purple)

measured with an Ocean Optics USB 4000-UV-IR spectrometer, calibrated with an optical fiber and in integrating sphere, in the relative irradiance mode, resulting in reduced the light losses and eliminated the spectral distortion. A comparison between the solar spectrum in Quito (latitude: $0^{\circ} 13^{\prime} \mathrm{S}$; longitude: $78^{\circ} 31^{\prime} \mathrm{W}$ ) and the spectra taken for the lamp is depicted in Fig. 2. It can be noted that the spectral match was effective in bringing the spectrum of the lamp closer to the solar one. Our homemade solar simulator produces high intensity and uniform illumination on a target spot area of $25 \mathrm{~mm}^{2}$, target spot area of $25 \mathrm{~mm}^{2}$, where the current-voltage curves achieve an intensity of 1 sun defined as equal to $100 \mathrm{~mW} \mathrm{~cm} \mathrm{~cm}^{-2}$ standard AM 1.5 G (AM: air mass) in order to comply with IEC 904-9, JIS C 8912-1989 and ASTM E927-05 standards. The solar simulator was used as a reference light source for testing dye-sensitized solar cells.

\section{Morphological characterization of the $\mathrm{TiO}_{2}$ film}

In DSSC assembly it is difficult to uniformly coat nanoporous $\mathrm{TiO}_{2}$ films onto the FTO surface using screen printing, which creates difficulties in getting SEM image when the films are not uniformly spread out. The detailed morphology of the $\mathrm{TiO}_{2}$ film used in DSSC fabrication was characterized by SEM. The SEM images (Fig. 3) of $\mathrm{TiO}_{2}$ nanoparticles dope one after another layer in order to find the optimum number of layers coated onto FTO glass by screen-printing technique. Examination of the first $\mathrm{TiO}_{2}$-coated layer shows nanoparticles agglomerated and void spaces along the surface (Fig. $3 \mathrm{a}$ ); the second $\mathrm{TiO}_{2}$ layer coated shows a uniform nanoparticles distribution (Fig. 3b). Whereas the third $\mathrm{TiO}_{2}$ layer coated shows a uniform sizes of $\mathrm{TiO}_{2}$ nanoparticles that enables a well-interconnected porous network structure of the $\mathrm{TiO}_{2}$ film needed for efficient dye adsorption (Fig. 3c), this remarkable improvement in morphology is deformed by the fourth (Fig. 3d) and fifth (Fig. 3e) $\mathrm{TiO}_{2}$-coated layers, since both exhibit cracks onto the $\mathrm{TiO}_{2}$ film assembled surface, along with irregular lumps formed on the substrate after screen-printing deposition, in consequence a non-uniform morphology. This suggests that during the sintering of $\mathrm{TiO}_{2}$ film thickness surface, the nanoparticles changed their size and shape and arranged them in non-uniform morphology. Consequently, three $\mathrm{TiO}_{2}$ film layers coated onto the FTO were selected as optimum $\mathrm{TiO}_{2}$ film wall thickness. Figure 4 exhibits three-dimensional atomic force microscopy (AFM), the average wall thickness of one $\mathrm{TiO}_{2}$ film layer achieved $2929 \mu \mathrm{m}$ of wall thickness roughness $(11.2 \pm 2.93 \mathrm{~nm})$, for two $\mathrm{TiO}_{2}$ film layers $5.85 \mu \mathrm{m}$, roughness $(13.5 \pm 1.52 \mathrm{~nm})$, and for three $\mathrm{TiO}_{2}$ film layers $8.78 \mu \mathrm{m}$, roughness $(14.3 \pm 4.23 \mathrm{~nm})$; these values are close with those 


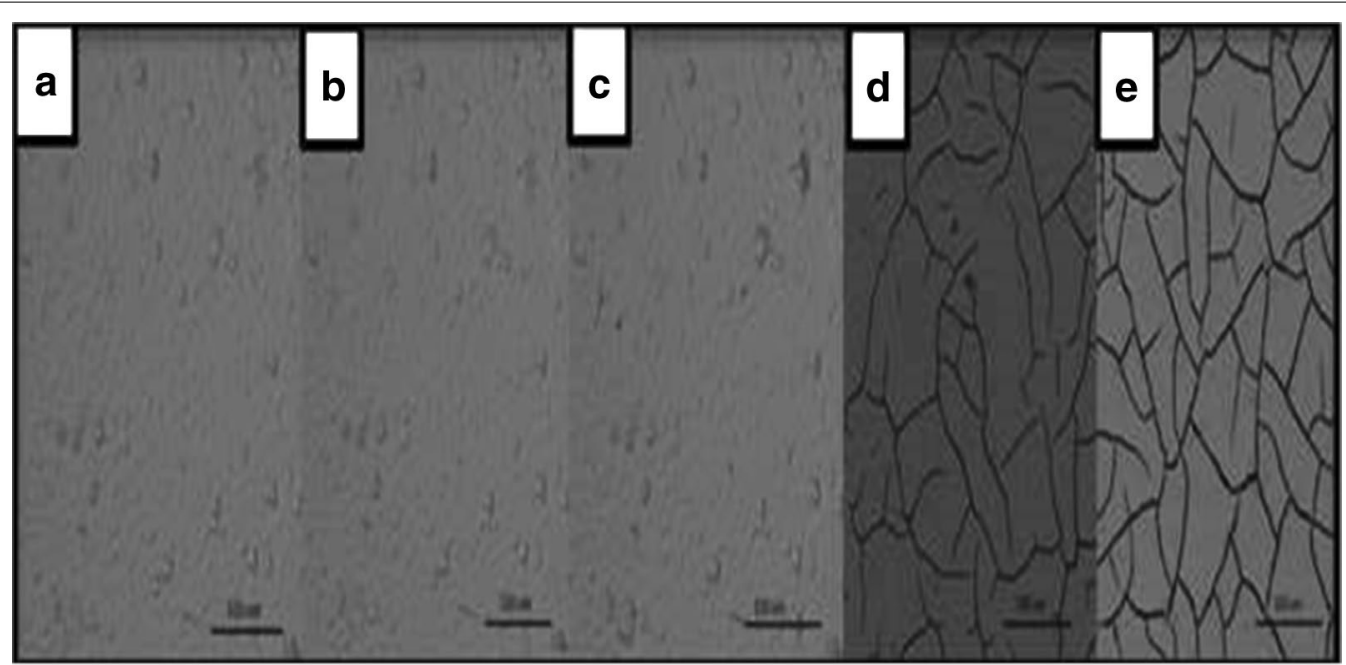

Fig. 3 SEM images of $\mathbf{a}$ one layer, $\mathbf{b}$ two layers, $\mathbf{c}$ three layers, $\mathbf{d}$ four layers and $\mathbf{e}$ five $\mathrm{TiO}_{2}$ layers coated on $\mathrm{FTO}$ glass by screen-printing technique, respectively

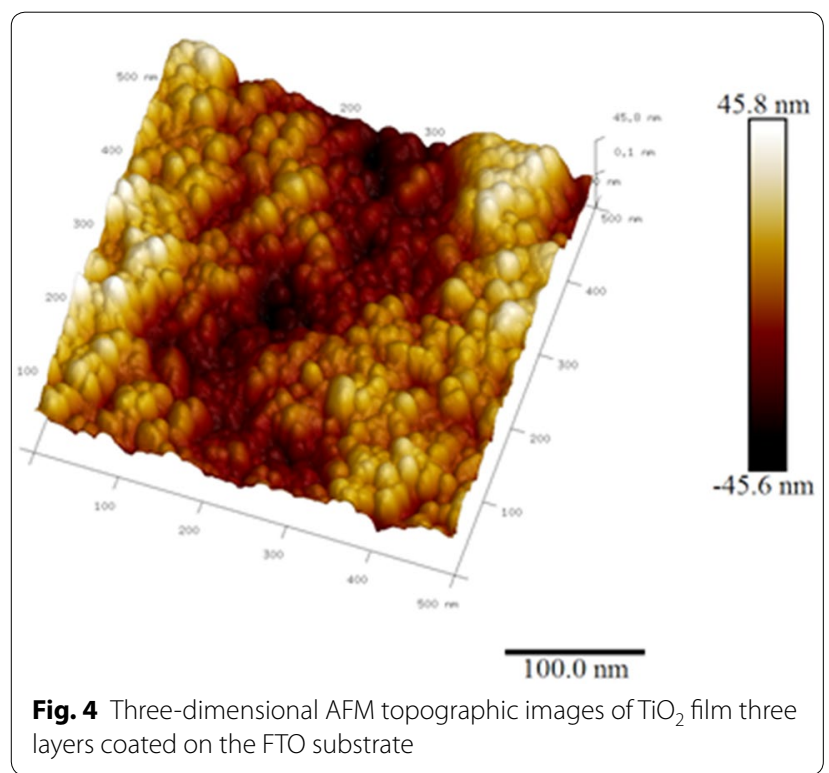

reported in the literature, $10 \mu \mathrm{m}$ of $\mathrm{TiO}_{2}$ film thickness, and $14 \mathrm{~nm}$ roughness (Kim et al. 2008; Nayaran 2012). This nanostructure arrangement developed may improve, light harvesting, vegetable dye adsorption on the surface of nanostructured $\mathrm{TiO}_{2}$ film, and the PCE of DSSCs.

\section{Absorption spectra of vegetable dyes photosensitizers}

The UV-Vis absorption in solution of eight kinds of representational vegetable dyes selected as photosensitizers for DSSCs is listed in Table 1. Figure 5 displays the representative UV-Vis absorption spectra and images for the ethanol extract solutions at $\mathrm{pH} 1$ of Jamaica flowers (Fig. 4a) and Mortiño fruit (Fig. 4b), respectively. As exhibited in Table 1, the ethanol extracts of Jamaica flowers extract exhibit maximum absorption peak at $520 \mathrm{~nm}$, and Mortiño fruit extract is about $536.5 \mathrm{~nm}$, Ataco leaves $665 \mathrm{~nm}$, Achiote seeds $454.5 \mathrm{~nm}$, Berenjena skins $423 \mathrm{~nm}$, Mora fruits $525 \mathrm{~nm}$, Rabano skins $504.5 \mathrm{~nm}$, and Tomate de arbol fruit $543 \mathrm{~nm}$. The difference in the absorption spectra could be due to the different colors of the extracts from Mortiño fruit (deep red blue) to Achiote seeds (red), as well as to their identical components in their chemical structure. In fact, anthocyanins, a group of natural phenolic compounds are involved in a series of $\mathrm{pH}$ dependent giving rise to different chemical species; the bright red coloration in the extracts is due to equilibrium shift of anthocyanin toward their flavylium cation $\mathrm{AH}^{+}$at low pH (Calogero et al. 2015; Lim et al. 2015). In general, predominance of hydroxyl groups on the aromatic skeleton of anthocyanin gives rise to an intense blue color, while a red color is observed when methoxyl groups prevail instead (Vekariya et al. 2016; Nayaran 2012). Anthocyanin compounds have also reported to be found in mora (berries), berenjena (eggplant), rabano (radish), tomate de arbol (tamarillo), ataco (amaranthaceae) and achiote (Wongcharee et al. 2007; Polo and Iha 2006; Cabrera et al. 2017; Tekerek et al. 2011; Chang and Lo 2010). Corresponding natural dyes extracted in ethanol were evaluated as photosensitizers of DSSC, for example, Jaboticaba skin (Myrciaria cauliflora) reported a maximum absorption peak at $538 \mathrm{~nm}$, attributed to peonidin as the principal anthocyanin compound (Polo and Iha 2006); it was also found that the absorption peak 
Table 1 Photoelectrochemical parameters of the DSSCs using extracts of vegetable dyes extracted with ethanol at pH 1, and $\mathrm{Ru}(\mathrm{N}-\mathbf{7 1 9})$ dye as photosensitizers

\begin{tabular}{|c|c|c|c|c|c|}
\hline Vegetable dye & $\lambda_{\max }(\mathrm{nm})^{\mathrm{b}}$ & $\left.J_{s c}\left(m_{A ~ c m}\right)^{-2}\right)^{a}$ & $V_{\text {oc }}(\mathrm{V})^{\mathrm{a}}$ & $\mathrm{FF}^{\mathrm{a}}$ & PCE (\%) ${ }^{a}$ \\
\hline Ataco & 665 & $0.06 \pm 0.00$ & $0.48 \pm 0.067$ & $0.66 \pm 0.05$ & $0.018 \pm 0.003$ \\
\hline Achiote & 454.5 & $0.06 \pm 0.02$ & $0.45 \pm 0.01$ & $0.50 \pm 0.78$ & $0.013 \pm 0.006$ \\
\hline Berenjena & 413 & $0.04 \pm 0.01$ & $0.40 \pm 0.12$ & $0.56 \pm 0.11$ & $0.008 \pm 0.003$ \\
\hline Flor de Jamaica & 520 & $0.382 \pm 0.061$ & $0.478 \pm 0.220$ & $0.580 \pm 0.025$ & $0.109 \pm 0.017$ \\
\hline Mora & 525 & $0.28 \pm 0.07$ & $0.48 \pm 0.02$ & $0.51 \pm 0.03$ & $0.069 \pm 0.020$ \\
\hline Mortiño & 536.5 & $0.557 \pm 0.147$ & $0.484 \pm 0.006$ & $0.664 \pm 0.043$ & $0.175 \pm 0.034$ \\
\hline Rabano & 504.5 & $0.07 \pm 0.01$ & $0.39 \pm 0.02$ & $0.55 \pm 0.06$ & $0.015 \pm 0.001$ \\
\hline Tomate de arbol & 543 & $0.10 \pm 0.02$ & $0.44 \pm 0.03$ & $0.52 \pm 0.04$ & $0.023 \pm 0.003$ \\
\hline Ru (N719) & 521.5 & $19.370 \pm 2.053$ & $0.750 \pm 0.018$ & $0.580 \pm 0.023$ & $8.39 \pm 0.54$ \\
\hline
\end{tabular}

${ }^{\mathrm{a}}$ Mean $\pm 95 \%$ confidence interval, $n=8$ values; ${ }^{\mathrm{b}} \lambda_{\max }$ in the visible range

of rosella flowers (Hibiscus sabdariffa) extract was about $520 \mathrm{~nm}$, and the anthocyanins obtained from rosella were delphinidin and cyaniding (Calogero et al. 2012, 2015; Borras-Linares et al. 2015), whereas an absorption peak of blue pea extracts was about $580-620 \mathrm{~nm}$, responsible for its blue color, and the anthocyanin obtained was ternatin (Wongcharee et al. 2007).

Figure 6 displays the adsorption spectrums of Jamaica flowers (A) and Mortiño fruit (B) onto $\mathrm{TiO}_{2}$ film structured in three layers, respectively. The absorption peak of Jamaica flowers at $520 \mathrm{~nm}$ in ethanol solution (Fig. 5a) is shifted to red at about $530 \mathrm{~nm}$ when the dye was adsorbed onto $\mathrm{TiO}_{2}$. Dyes extracted with ethanol at $\mathrm{pH} 1$, and $\mathrm{Ru}$ (N-719) dye as photosensitizers. Hence, the absorption spectrums of Jamaica flowers and Mortiño fruit extracts onto $\mathrm{TiO}_{2}$ surface appear wider and redshift compared with that in ethanol solution, respectively. The difference in the absorption peaks may be due to the binding of different types of anthocyanins in the extract adsorbed onto the $\mathrm{TiO}_{2}$ surface. This difference between anthocyanins is mainly due to the number of $\mathrm{OH}^{-}$and $\mathrm{OCH}_{3}$ groups (Table 2). In general, the photovoltaic performance of DSSCs is related to the surface characteristics of the $\mathrm{TiO}_{2}$ semiconductor as well as the photosensitizer. Earlier studies have reported that chemical adsorption scheme of anthocyanins onto active adsorption sites on the $\mathrm{TiO}_{2}$ surface is the result of alcoholic bound protons which condense with hydroxyl groups present at the surface of nanostructured $\mathrm{TiO}_{2}$ film forms strong complexes showing generally the quinonodial form, which emerges from $-\mathrm{OH}$ or $=\mathrm{O}$ groups and $\mathrm{Ti}(\mathrm{IV})$ sites on the semiconductor nanocrystalline layer (Cherepy et al. 1997; Calogero et al. 2012). The attachment to the $\mathrm{TiO}_{2}$ surface stabilizes the exited state and thus shifts toward the lower energy of the absorption maximum (Cabrera et al. 2017).

Anthocyanins as dye photosensitizers are able to bind with the active sites onto the surface of the $\mathrm{TiO}_{2}$ nanoparticles, which are mainly due to the presence of hydroxyl functional groups; this binding will facilitate electron transfer from anthocyanin molecules to the conduction 

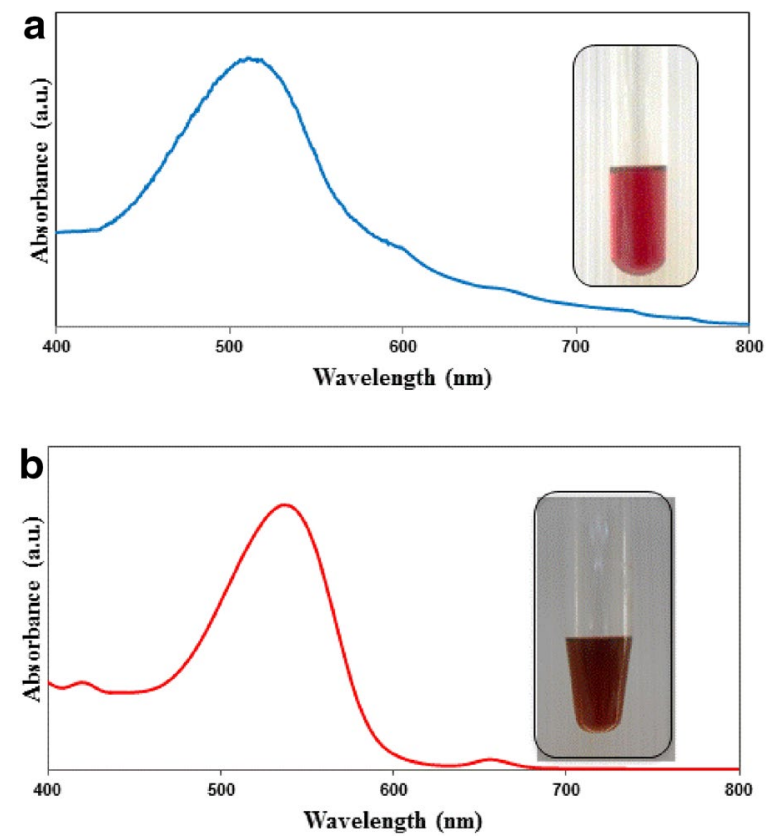

Fig. 5 Absorption spectrum of a Jamaica flowers and $\mathbf{b}$ the Mortiño fruit

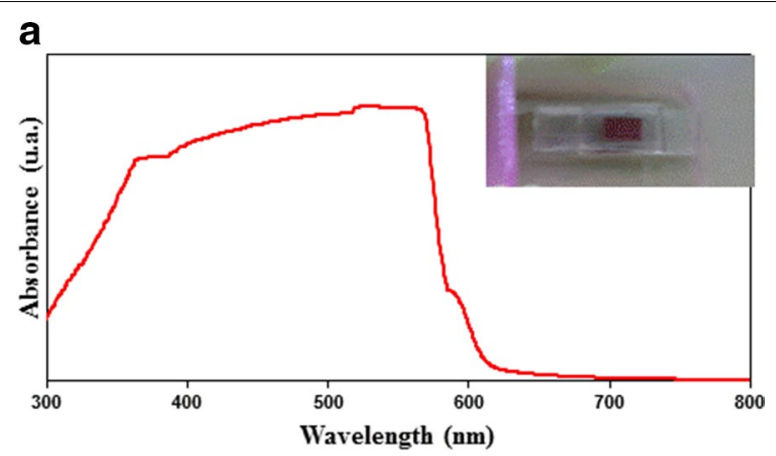

b

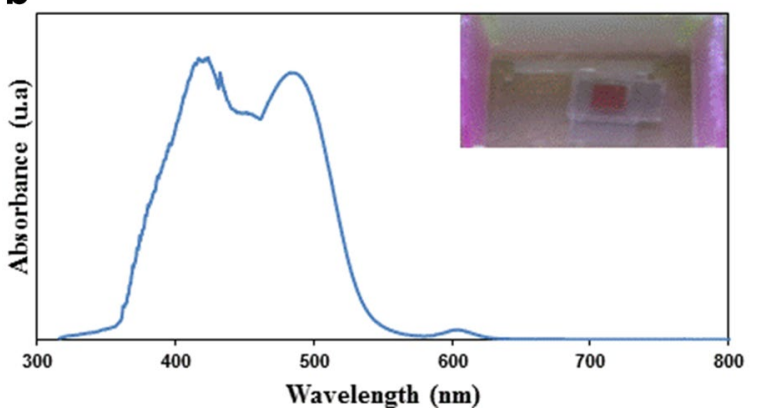

Fig. 6 Absorption spectra of a Jamaica flowers onto $\mathrm{TiO}_{2}$ and $\mathbf{b}$ Mortiño fruit adsorbed onto $\mathrm{TiO}_{2}$ surface

band of $\mathrm{TiO}_{2}$. As Table 2 depicts, the sensitizing performance of anthocyanins differs from one another depending upon the sources from where anthocyanins are being extracted. In this particular case, anthocyanin becomes the main dye component in Jamaica flowers and Mortiño fruit, the stability of anthocyanins extracted in both vegetable dyes is maintained constant in ethanol solution at $\mathrm{pH} 1$, as explained above. Therefore, when each vegetable dye is adsorbed on the surface of nanostructured $\mathrm{TiO}_{2}$, photo-anode maintains its respective color after exposed to the homemade solar simulator sunlight for more than $8 \mathrm{~h}$ per 2 consecutive days a week during a period of 2 weeks; no appreciable degradation was observed during this preliminary tests of stability suggesting that the type of anthocyanins adsorbed onto $\mathrm{TiO}_{2}$ photo-anode is stable and resistant to photocatalytic degradation (Fig. 6), and for that matter suitable for DSSCs fabrication.

\section{Performance of DSSCs sensitized with Jamaica flowers and Mortiño fruit}

Photovoltaic test of DSSCs using eight vegetable dye extracts as photosensitizers was performed by measuring the current voltage $(I-V)$ curves under irradiation with light $\left(100 \mathrm{~mW} \mathrm{~cm}{ }^{-2}\right)$ from homemade solar simulator. Table 1 summarizes the performance of the DSSCs in terms of short-circuit photocurrent $\left(J_{\mathrm{sc}}\right)$, open-circuit voltage $\left(V_{\mathrm{oc}}\right)$, fill factor $(\mathrm{FF})$, and power conversion efficiency (PCE) compared to artificial dye N719, the fill FF ranges from 50 to $66 \%$, the $V_{\text {oc }}$ varies from 0.40 to $0.48 \mathrm{~V}$, and the $J_{\mathrm{sc}}$ changes from 0.06 to $0.56 \mathrm{~mA} \mathrm{~cm}{ }^{-2}$, and PCE fluctuates from 0.01 to $0.18 \%$. Specifically, Fig. 7 shows the typical $I-V$ curves of the DSSCs using the photosensitizer dyes extracted from Mortiño fruit and Jamaica flowers. The average values of $V_{\text {oc }}(0.484 \mathrm{~V})$ and $J_{\mathrm{sc}}\left(0.557 \mathrm{~mA} \mathrm{~cm}^{-2}\right)$, and PCE $(0.175 \pm 0.034 \%)$ were achieved from the DSSC sensitized by Mortiño fruit extract, in comparison to the DSSC sensitized by Jamaica flowers extract, corresponding values of $V_{\text {oc }}(0.478 \mathrm{~V})$ and $J_{\mathrm{sc}}\left(0.382 \mathrm{~mA} \mathrm{~cm}^{-2}\right)$ and PCE $(0.109 \pm 0.017 \%)$. No decrease in $J_{\mathrm{sc}}$ was observed when tested the DSSCs sensitized with each one of the vegetable dyes, suggesting a good stability of the DSSCs for more than $32 \mathrm{~h}$. The fill factors of the DSSC sensitized by Mortiño fruit dye extracts and the DSSC sensitized by N719 are comparable $58.2 \%$, and both are lower than the DSSC sensitized by Jamaica flowers dye extract (60.5\%).

These results suggest that the interaction between the photosensitizer and the active sites onto nanoporous $\mathrm{TiO}_{2}$ film is significant in enhancing the energy conversion efficiency of DSSC sensitized by Mortiño fruit rather than Jamaica flowers. The measured efficiencies are equivalent or higher than those reported in other investigations for DSSCs based on anthocyanins as photosensitizers: blueberry and black raspberry $(\mathrm{PCE}=0.034-0.05 \%)$ (Tekerek eet al. 2011), blue pea $(\mathrm{PCE}=0.05 \%)$ (Wongcharee et al. 2007), Hibiscus 


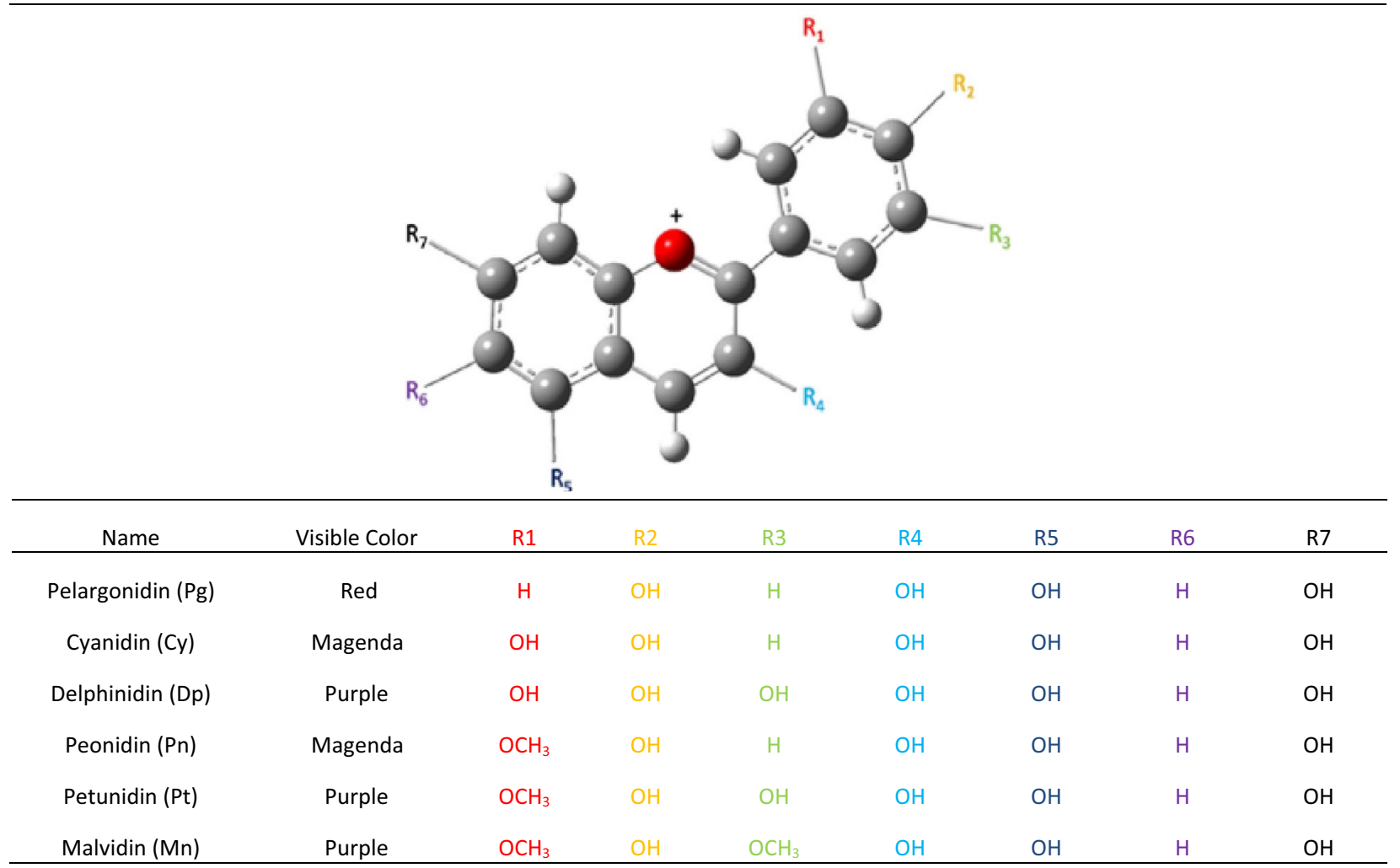

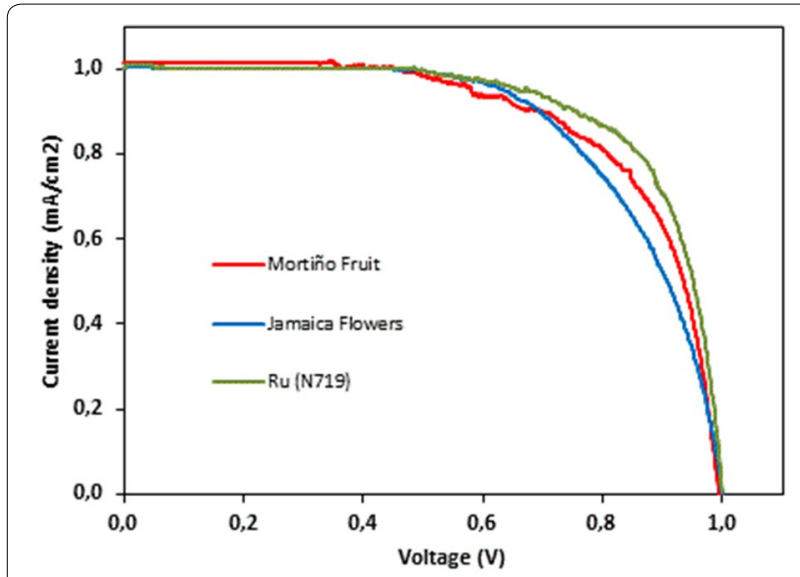

Fig. 7 Current-voltage curves for the DSSCs sensitized with extracts of a Jamaica flowers and b Mortiño fruit and c N719 dye

sabdariffa (Zobo) $\quad(\mathrm{PCE}=0.033 \%) \quad$ (Ahmdian 2011), Khella $(\mathrm{PCE}=0.05 \%)$, Red cabbage, Brassica olercea $(\mathrm{PCE}=0.13 \%)$ (Ludin et al. 2014), lithospermum $(\mathrm{PCE}=0.03 \%)$, Lily $(\mathrm{PCE}=0.17 \%) \quad$ (Gokilmeni et al. 2013). Conversely, our results are lower or comparable to those achieved in other studies: Black carrot (Daucus carota L) $(\mathrm{PCE}=0.25 \%)$ (Tekerek et al. 2011), Rosella
$(\mathrm{PCE}=0.35 \%)$ (Wongcharee et al. 2007), Punica granatum (Pomegranate) $(\mathrm{PCE}=0.59 \%)$ (Chang and Lo 2010), Lawsonia inermis (Henna) $(\mathrm{PCE}=0.66 \%)$ (Ludin et al. 2014), shiahkooti fruits (PCE $=0.73 \%$ ) (Mozaffari et al. 2015), Sesbania grandflora ( $\mathrm{PCE}=1.02 \%$ ) (Suhaimi et al. 2015), Hibiscus surattensis ( $\mathrm{PCE}=1.14 \%$ ) (Wongcharee et al. 2007), Rhuc/sumas fruits $(\mathrm{PCE}=1.5 \%)$ (Suhaimi et al. 2015), punica grantum peel $(\mathrm{PCE}=0.1 .86 \%)($ Hernandez-Martinez et al. 2012).

The performance of DSSC may be affected for the type of adsorption between anthocyanins and $\mathrm{TiO}_{2}$ pore structure; if the pores are close to the size of the dye molecules, more adsorption may occur until the pores are filled with anthocyanin. Accordingly, the structure of the anthocyanins may also affect the performance of DSSC. For example, if the structure has longer R group, this results in the steric hindrance for the anthocyanin to form bond with the oxide surface of the $\mathrm{TiO}_{2}$ (Calogero et al. 2015; Cabrera et al. 2017). Hence, it prevents the molecule from chemical adsorption on the $\mathrm{TiO}_{2}$ film effectively. Anthocyanin molecules can absorb light photons and lead to production of exited electrons, but when there is no free space between the dyes, molecules might tackle the physical contact between the iodine solution and $\mathrm{TiO}_{2}$ semiconductor. Thus, reducing reaction 
and lack of electron transfer from the anthocyanin to the conduction band of $\mathrm{TiO}_{2}$ inhibit the conversion efficiency of DSSCs (Zhou et al. 2011). Hence, Jamaica flowers and Mortiño dyes originally from the northern Andes of South America where these dyes are widely available at elevations from 6000 to $13,000 \mathrm{ft}$, above the sea level, should be considered as an alternative of anthocyanin source for DSSC preparation.

\section{Purification and Absorption spectra of extracts from Jamaica flowers and Mortiño fruit}

Earlier studies have reported that the type of solvent affects the absorption spectrum of the dyes as well as the bonding between the dyes and the active sites onto the $\mathrm{TiO}_{2}$ surface (Calogero et al. 2015; Wongcharee et al. 2007; Lee et al. 2015). Anthocyanins are more soluble in ethanol, but the aggregation of the dye molecules is less than expected (Wongcharee et al. 2007; Zhou et al. 2011). Thus, aggregation is expected to be strongly dependent on the properties of solvents, which could improve the dye molecules dispersion and adsorption on the active sites of $\mathrm{TiO}_{2}$ porous surface. Furthermore, anthocyanins as polar molecules have been extracted using the most common aqueous mixtures of ethanol, methanol or acetone. Solvents without purification are able to coextract a great number of other compounds such as nonphenolic substances (Warkkoyo 2011; Zhou et al. 2011). Thereby, a novel purification method was implemented to explore the feasibility of improving the conversion efficiencies of DSSCs sensitized by ethanol extracts from Mortiño fruit and Jamaica flowers dyes. The purification method consisted in liquid-liquid extraction of various components of the ethanol extracts using different organic solvents of different polarity as shown in Fig. 8. The technique involves the use of two immiscible solvents in a separating funnel, in which compounds are distributed in the solvents according to their different partition coefficients (Nayaran 2012; Costa-Rocha et al. 2014). After retrograde evaporation of each dye sample, two extract solutions were obtained. Solution A corresponded to ethanol fraction, separated from the precipitated corresponded dye after water extraction, and solution $B$, which was purified by liquid-liquid extraction with different solvents, namely, petroleum ether, chloroform, ethyl acetate, $n$-butanol, and distilled water. Among the five solvents only petroleum ether extracts were colorless for each vegetable dye, the others develop different red color of different intensities. The impact of solvents on the absorption spectra of the Jamaica flowers and Mortiño fruit extracts purified by liquid-liquid extraction with distilled water, ethanol, $n$-butanol, ethyl acetate, and chloroform are illustrated in Fig. 9. The absorbance of both vegetable dyes displays

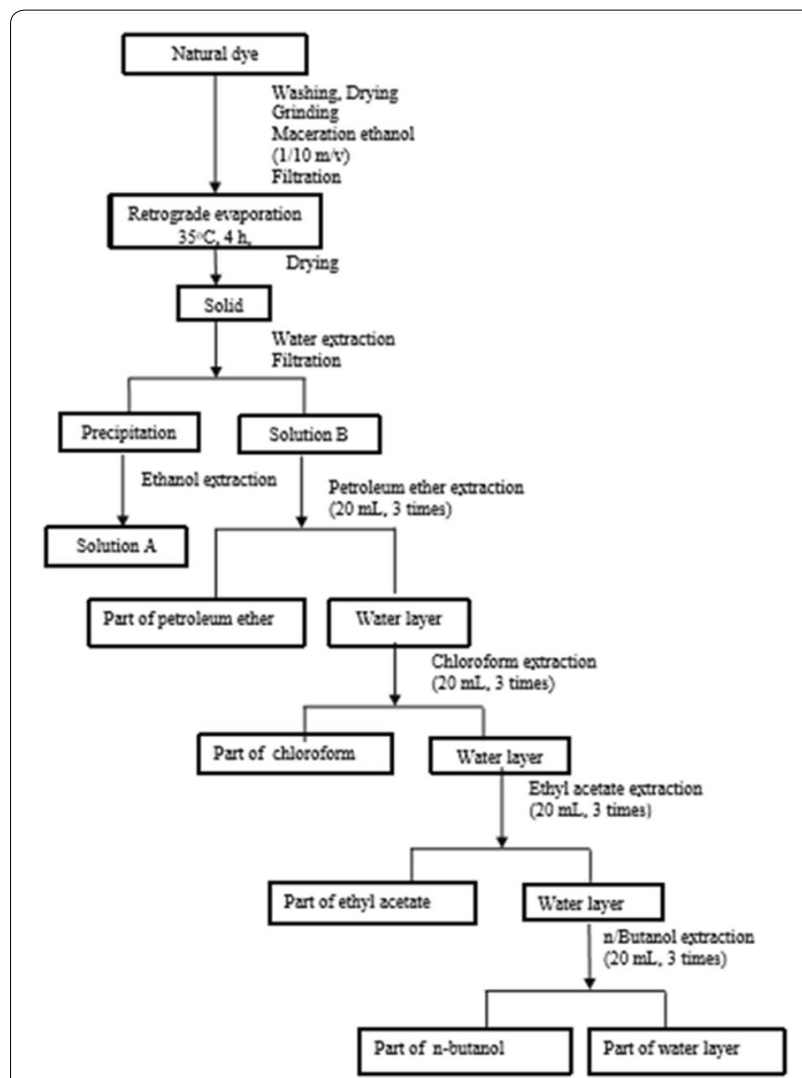

Fig. 8 Purification scheme of the extracts recovered from Mortiño fruit and Jamaica flowers

an ample range of wavelength frequency within the visible range, 450-700 $\mathrm{nm}$. Figure 9a illustrates the maximum absorption peaks at $540 \mathrm{~nm}$ corresponding to the Jamaica flowers dye extracted in ethanol and solution $B$ at $520 \mathrm{~nm}$, which is approximately the superposition of four parts ethyl acetate, chloroform, $n$-butanol and distilled water, which agrees with the findings in the literature (Zhou et al. 2011). In fact, the dye extracted in ethyl acetate shows an intense absorption at a wavelength of approximately $545 \mathrm{~nm}$, followed by chloroform $535 \mathrm{~nm}$, n-butanol $525 \mathrm{~nm}$, and water $542 \mathrm{~nm}$, respectively. These absorption peaks observed correspond with the absorption spectra of anthocyanins, as reported (Abdou et al. 2013; Wongcharee et al. 2007). Anthocyanins content in rosella flowers (Hibiscus sabdariffa) extracts were identified as having delphinidin-3-sambubioside (70\% of the anthocyanins) and cyaniding-3-sambubioside as the major dyes, with delphinidin-3-glucoside and cuanidin3 -glucoside as the minor ones (Fig. 10), which agrees with the findings in the literature (Mozaffari et al. 2015; Aduloju et al. 2011; Shalini et al. 2015). Hence, the difference in the absorption characteristics is due to the different type of anthocyanin content and color of the extracts. 

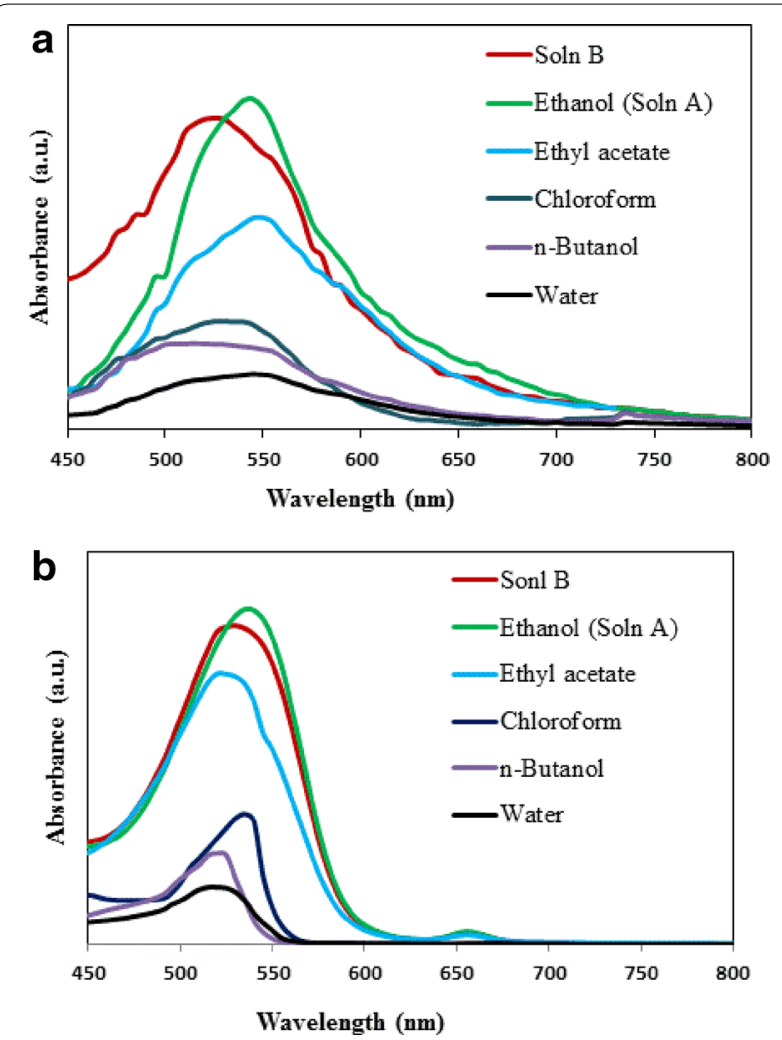

Fig. 9 UV-vis absorption spectrum of the extracts with different solvents from $\mathbf{a}$ Jamaica flowers and $\mathbf{b}$ Mortiño fruit

Ahmdian 2011 reported the interaction of some organic acids with anthocyanins and the way they affect their coloration (co-pigmentation effect). From the absorbance results, besides ethanol, ethyl acetate appears as the best solvent to extract anthocyanins from Jamaica flowers. Polar aprotic and protic solvents were reported as the two polar solvents commonly used to extract anthocyanins, but more of them were extracted when using polar aprotic than protic solvents including dimethyl formamide, ethanol and distilled water as the extraction solvent, in agreement with our findings (Nayaran 2012). Figure 9b displays the UV-Vis absorption spectra of the Mortiño fruit extracted with different solvents within the visible range $450-610 \mathrm{~nm}$. The dye extracted in ethanol and solution B exhibits the highest absorption peaks at $535 \mathrm{~nm}$ and $530 \mathrm{~nm}$, respectively. In addition, ethyl acetate absorption peak at a wavelength of $525 \mathrm{~nm}$ is followed by chloroform at about $535 \mathrm{~nm}$, of $n$-butanol at $525 \mathrm{~nm}$, and of water at about $520 \mathrm{~nm}$, respectively. In light of the above, intense absorption peaks detected between 500 and $550 \mathrm{~nm}$ supporting the presence of anthocyanin molecules. Therefore, ethyl acetate appears as the optimum solvent for anthocyanins obtained from solution B for Jamaica flowers, equally for Mortiño fruit, followed by chloroform, $n$-butanol and distilled water. This indicates that the anthocyanins extracted from each vegetable dye dissolve better in polar aprotic solvent such as ethyl acetate, demonstrating the importance of selecting a suitable solvent for anthocyanin purification. Similar findings have been reported by other researchers, they revealed that polar aprotic solvent such as dimethyl formamide, dimethyl sulfoxide, and acetone managed to extract more anthocyanins from Ixora coccinea flower than those of polar protic solvents such as ethanol and distilled water (Lim et al. 2015; Wongcharee et al. 2007; Cabrera et al. 2017).

\section{Performance of DSSCs sensitized with extracts purified from Jamaica flowers and Mortiño fruit}

As observed in Table 3, the DSSC photosensitized by the dyes extracted and purified from Jamaica flowers in ethyl acetate achieved average values for $J_{\mathrm{sc}}$ of $0.678 \mathrm{~mA} \mathrm{~cm}^{-2}$, a $V_{\text {oc }}$ of $0.541 \mathrm{~V}$, and a FF of 0.579 , corresponding to a PCE of $0.217 \%$. This performance is higher than that of the dyes extracted and purified in ethanol $(0.121 \%)$, chloroform (0.1\%), $n$-butanol $(0.077 \%)$, and distilled water (the lowest $0.01 \%$ ), respectively. Besides, the PCE of DSSC using solution B $(0.039 \%)$ is much lower than the sum of the efficiencies of the DSSCs sensitized with extracts of chloroform, ethyl acetate, $n$-butanol and distilled water. These results suggest that the mixed extract adsorbed on $\mathrm{TiO}_{2}$ film surface does not show synergistic light absorption and photosensitization when compared with individual extracts. This can be attributed to the lower anthocyanin content and limited solubility in Jamaica flowers extracted in solution B than in the other solvents. As it was described above, the structure of the anthocyanin complexes identified in Hibiscus sabdariffa has longer R groups (Fig. 10) and hence, the strong steric hindrance of these complexes may prevent the anthocyanin molecules from effectively arraying on the surface of $\mathrm{TiO}_{2}$ film, in agreement with other studies reported in the literature (Lim et al. 2015; Polo and Iha 2006; Snaith 2010).

The best performance of DSSC sensitized by the dyes extracted and purified from Mortiño fruit in ethyl acetate achieved $(\mathrm{PCE}=0.332 \pm 0.018 \%)$ with averages values of $V_{\mathrm{oc}}(0.52 \mathrm{~V}), J_{\mathrm{sc}}\left(1.014 \mathrm{~mA} \mathrm{~cm} \mathrm{~cm}^{-2}\right)$, and FF (0.611). This achievement is by far higher than the DSSCs sensitized by the dyes extracted and purified in: $n$-butanol $(\mathrm{PCE}=0.0961 \pm 0.005 \%)$; chloroform $(\mathrm{PCE}=0.177 \pm 0.024 \%)$; ethanol $(\mathrm{PCE}=0.212 \pm 0.036 \%)$; and distilled water (the lowest $\mathrm{PCE}=0.084 \pm 0.011 \%$ ), respectively. Comparable results of PCEs have reported in literature, for DSSCs photosensitized by dyes extracted from Ixora coccinena flower with six different solvents. As a matter of fact, the DSSC assembled using a 
<smiles>[M]COc1cc2c(O)cc(O)cc2[o+]c1C(=O)c1ccc(O)c(O)c1</smiles>

Cyanidin 3-sambubioside<smiles>O=C(/C(=C\c1c([O-])cc(O)cc1O)OC1CCCCC1)c1ccc(O)c(O)c1</smiles>

Cyanidin 3-glucoside<smiles>[M]O[Ge]OC(=Cc1c([O-])cc(O)cc1O)C(=O)c1cc(O)c(O)c(O)c1</smiles>

Delphinidin 3-sambubioside<smiles>O=C(/C=C\c1c(O)cc(O)cc1C(=O)c1cc(O)c(O)c(O)c1)OC1CCCCC1</smiles>

Delphinidin 3-glucoside

Fig. 10 Chemical structures for anthocyanin compounds found in Hibiscus Sabdariffa

dye photosensitizer extracted in $70 \%$ ethanol achieved the highest conversion efficiency ( $\mathrm{PCE}=0.5 \pm 0.04 \%$ ), followed by acetone (PCE $=0.30 \pm 0.04 \%)$, absolute ethanol $(\mathrm{PCE}=0.27 \pm 0.01 \%)$, dimethyl formamide $(\mathrm{PCE}=0.17 \pm 0.01 \%)$, dimethyl sulfoxide $(\mathrm{PCE}=0.16 \pm 0.01 \%)$, and distilled water $(\mathrm{PCE}=0.09 \pm 0.003 \%)$, respectively (Lim et al. 2015). Consequently, the Mortiño fruit dye extracted and purified in ethyl acetate dye-based DSSC displayed superior PCE $(0.332 \%)$ almost 1.5 times higher than the Jamaica flowers extracted in ethyl acetate dye PCE $(0.217 \%)$. The DSSCs prepared with photosensitizer dyes extracted and purified in ethyl acetate showed higher PCEs compared to those assembled with ethanol extracts. Recognizing that $V_{\text {oc }}$ is directly proportional to the energy gap between the HOMO and the LUMO energy levels of the vegetable dyes and the energy levels of the semiconductor $\mathrm{TiO}_{2}$ (Nayaran 2012). The $V_{\text {oc }}$ of DSSCs sensitized with the dyes extracted and purified from Jamaica flowers in ethyl acetate, produced a higher voltage $(0.541 \mathrm{~V})$ compared to those in ethanol $(0.478 \mathrm{~V})$, producing $13 \%$ increment. Whereas the dyes extracted and purified from Mortiño fruit in ethyl acetate dye-based DSSC showed an increment from 0.484 to $0.520 \mathrm{~V}$, corresponding an 
Table 3 Photoelectrochemical parameters of DSSCs using extracts purified with different solvents from Jamaica flowers and Mortiño fruit as photosensitizers

\begin{tabular}{|c|c|c|c|c|}
\hline Solvent & $J_{s c}\left(m A c m^{-2}\right)^{a}$ & $V_{\text {oc }}(\mathrm{V})^{\mathrm{a}}$ & $\mathrm{FF}^{\mathrm{a}}$ & PCE $(\%)^{a}$ \\
\hline \multicolumn{5}{|l|}{ Jamaica flowers } \\
\hline Solution A & $0.438 \pm 0.084$ & $0.495 \pm 0.014$ & $50.589 \pm 0.034$ & $0.121 \pm 0.014$ \\
\hline Solution B & $0.177 \pm 0.000$ & $0.437 \pm 0.001$ & $00.491 \pm 0.001$ & $0.039 \pm 0.001$ \\
\hline Chloroform II & $0.466 \pm 0.027$ & $0.430 \pm 0.019$ & $00.499 \pm 0.003$ & $0.100 \pm 0.006$ \\
\hline Ethyl acetate III & $0.678 \pm 0.003$ & $0.541 \pm 0.003$ & $50.579 \pm 0.019$ & $0.217 \pm 0.007$ \\
\hline n-Butanol IV & $0.315 \pm 0.014$ & $0.438 \pm 0.003$ & $50.561 \pm 0.004$ & $0.077 \pm 0.003$ \\
\hline Distilled water $V$ & $0.051 \pm 0.001$ & $0.468 \pm 0.001$ & $00.409 \pm 0.001$ & $0.010 \pm 0.001$ \\
\hline \multicolumn{5}{|l|}{ Mortiño fruit } \\
\hline Solution A & $0.710 \pm 0.083$ & $0.474 \pm 0.001$ & $60.645 \pm 0.012$ & $0.212 \pm 0.036$ \\
\hline Solution B & $0.129 \pm 0.000$ & $0.435 \pm 0.000$ & $00.479 \pm 0.000$ & $0.028 \pm 0.000$ \\
\hline Chloroform II & $0.624 \pm 0.018$ & $0.557 \pm 0.002$ & $40.478 \pm 0.007$ & $0.177 \pm 0.024$ \\
\hline Ethyl acetate III & $1.014 \pm 0.036$ & $0.520 \pm 0.001$ & $60.611 \pm 0.014$ & $0.332 \pm 0.018$ \\
\hline n-Butanol IV & $0.368 \pm 0.02$ & $0.463 \pm 0.02$ & $50.567 \pm 0.002$ & $0.096 \pm 0.005$ \\
\hline Distilled water $V$ & $0.196 \pm 0.189$ & $0.303 \pm 0.296$ & $50.589 \pm 0.003$ & $0.084 \pm 0.011$ \\
\hline \multicolumn{5}{|l|}{ Ru-N719 } \\
\hline N719 & $24.08 \pm 5.80$ & $0.75 \pm 0.007$ & $50.546 \pm 0.066$ & $9.65 \pm 1.04$ \\
\hline
\end{tabular}

${ }^{a}$ Mean $\pm 95 \%$ confidence interval, $n=8$ values; $\lambda_{\max }$ in the visible range

increment of $7.5 \%$. Therefore, significant $V_{\text {oc }}$ increases using purification minimize energy loss of each vegetable dye-based DSSCs (Fig. 11).

The $J_{\mathrm{sc}}$ of DSSCs photosensitized with the dyes extracted and purified from Jamaica flowers in ethyl acetate with respect to the $J_{\mathrm{sc}}$ in ethanol produced $77.5 \%$ increment, from 0.382 to $0.678 \mathrm{~mA} \mathrm{~cm}^{-2}$. Whereas the corresponding $J_{\mathrm{sc}}$ values for DSSCs prepared with the dye extracted and purified from Mortiño fruit in ethyl acetate showed an increment of $82 \%$ from 0.557 to $1.014 \mathrm{~mA} \mathrm{~cm}^{-2}$, with respect to those in ethanol, respectively. Many previous studies examined that the $J_{\mathrm{sc}}$ has significant influence on the absorption capability of the vegetable dyes. Thus, the ability to absorb light was higher for the dye extracted and purified from Mortiño fruit than for those from Jamaica flowers, in agreement to the research conducted by other investigators (Sreekala et al. 2012; Al-Alwini et al. 2015). Besides the type and content of dyes extracted and purified in ethyl acetate from the Mortiño fruit may contain a high quantity of anthocyanins at its $\mathrm{pH}$ value. Due to the acceleration in the recombination rate of injected electrons with the electrolyte, the better light harvesting ability of anthocyanin, and the presence of $\mathrm{OH}^{-}$functional groups in the anthocyanin, it may promote chemical adsorption on active sites onto the $\mathrm{TiO}_{2}$ surface. This suggest that ethyl acetate among all the investigated solvents is the right medium for anthocyanin extraction and purification from Mortiño fruit dye. As well as the favorable solvent medium for efficient dye adsorption onto $\mathrm{TiO}_{2}$ surface.
The efficiency of DSSCs with anthocyanin extracted and purified in ethyl acetate from Mortiño fruit is better than that of DSSC with anthocyanin extracted without purification from most vegetable photosensitizers reported to date, but it remains lower than the measured PCE of the N719 dye-based DSSC.

\section{Conclusion}

Eight vegetable dyes including flowers, leaves of plants, fruits and seeds traditional Andean medicines and beverages originally from the Andes of South America available at elevations from 6000 to $13,000 \mathrm{ft}$, above the sea level were extracted with ethanol without purification and used as photosensitizer to nanofabricate DSSCs. The photoelectrochemical performance of the DSSCs photosensitized with the extracts of these vegetable dyes showed that $J_{\mathrm{sc}}$ varied from 0.04 to $0.56 \mathrm{~mA}$, the $V_{\mathrm{oc}}$ was in the range of $0.39-0.48 \mathrm{~V}$, and the PCE fluctuated from 0.01 to $0.18 \%$. Specifically, the DSSCs photosensitized by the ethanol extracts from Mortiño fruit and Jamaica flowers exhibited the highest $V_{\mathrm{oc}}$ and PCE values presumably due to the presence of anthocyanin, the main component in the extracts of both vegetable dyes. They were selected to further purification by liquid-liquid extraction of the ethanol extracts obtained from each dye using organic solvents of different polarity namely, petroleum ether, chloroform, ethyl acetate, $n$-butanol, and distilled water. Overall, the photoelectrical performance of the DSSCs was enhanced by the dye photosensitizer purified in ethyl acetate from 

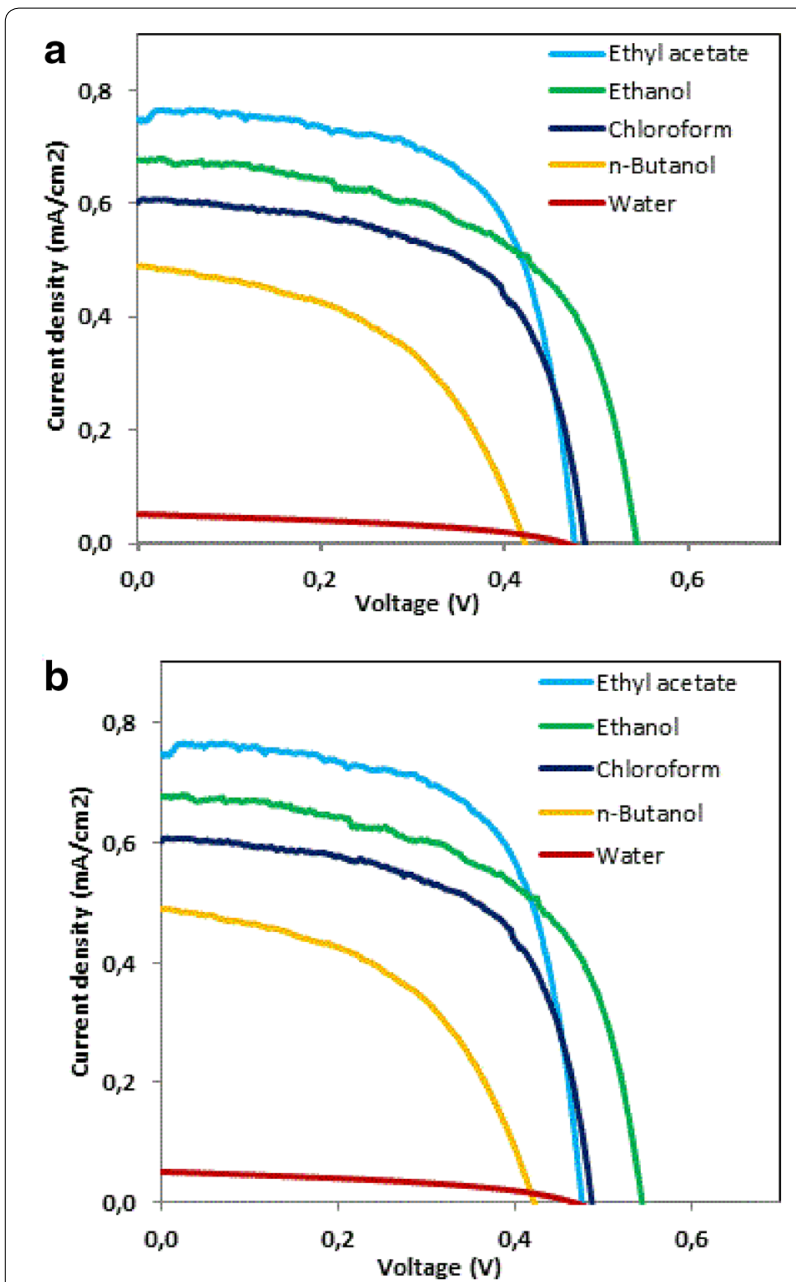

Fig. 11 Current density-voltage performances of the DSSCs assembled with $\mathbf{a}$ Jamaica flowers and $\mathbf{b}$ Mortiño fruit dyes extracted in different solvents

the ethanol extracts of Mortiño fruit and Jamaica flowers. The PCE of the DSSC nanofabricated with the dye extracted in ethyl acetate from Mortiño fruit achieved $0.33 \%$, with $V_{\text {oc }}$ of $0.520 \mathrm{~V}$ and $J_{\mathrm{sc}}$ of $1.014 \mathrm{~mA} \mathrm{~cm}^{-2}$, whereas the corresponding values obtained from the dye extracted from Jamaica flowers reached $0.22 \%$ with $V_{\text {oc }}$ of $0.541 \mathrm{~V}$ and $J_{\text {sc }}$ of $0.678 \mathrm{~mA} \mathrm{~cm}^{-2}$. Therefore, ethyl acetate resulted as the most favorable solvent for purification of ethanol extracts from Mortiño fruit and Jamaica flowers and increased the PCE of DSSCs by about twofold for each photosensitizer vegetable, respectively.

\section{Acknowledgements}

Authors gratefully acknowledge the support of the Ecuadorian Secretary of Higher Education Science and Technology (SENESCYT), the Prometheus program, and the laboratory of Chemistry at UTPL, and the farmers of the Andean region of South America who grow vegetable dyes in the Andean region of South America.

\section{Authors' contributions}

JR-P carried out collection, extraction in different solvents and spectrophotometric characterization of vegetable dyes, participated in the fabrication and photoelectrochemical characterization of the DSSCs, and drafted the manuscript and the revision process. CM conceived the study, and participated in its design, assembled and characterization of the DSSCs. CPS participated in the development of the software design, calibration and measurement the photoelectrochemical properties of DSSCs under homemade solar simulator. All authors read and approved the final draft manuscript.

\section{Funding}

Funding to carry out this research was provided by SENESCY under Prometheus Research Fellowship and Universidad Tecnica Particular de Loja (UTPL) through a University Grant Commission Govt. of Ecuador.

\section{Availability of data and materials}

Experimental data are available in excel spreadsheet for each dye; due to long file, it will available upon request and store in a repository.

\section{Competing interests}

The authors declare that they have no competing interests.

\section{Author details}

${ }^{1}$ Departmento de Química y Ciencias Exactas, Universidad Técnica Particular de Loja, San Cayetano Alto, Loja, Ecuador. ${ }^{2}$ Department of Chemistry and Biochemistry, Kent State University at Stark, 6000 Frank Ave NW, North Canton, $\mathrm{OH} 22720$, USA. ${ }^{3}$ Departamento de Física, Escuela Politécnica Nacional, Ladron de Guevara E11-253, Quito, Ecuador.

Received: 29 May 2018 Accepted: 10 June 2019

Published online: 24 June 2019

\section{References}

Abdou, E. M., Hafez, H. S., Bakir, E., \& Abdel-Mottaleb, M. S. A. (2013). Photostability of low cost dye-sensitized solar cells based on natural synthetic dyes. Spectrochimica Acta Part A: Molecular and Biomolecular Spectroscopy, 115, 202-207.

Aduloju, K. A., Mohamed, B. S., \& Simiyu, J. (2011). Effect of extracting solvents on the stability and performances of dye-sensitized solar cell perpared using extract from Lawsonia inermis. Fundam J Mod Phy, 1, 261-268.

Ahmdian, R. (2011). Estimating the impact of dye concentration on the photoelectrochemical performance of anthocyanin-sensitized solar cells: A power law model. Journal of Photonics for Energy, 1, 1-11.

Al-Alwini, M. A. M., Mohamad, A. B., Kadhum, A. A. H., \& Ludin, N. A. (2015). Effect of solvents on the extraction of natural pigments and adsorption onto $\mathrm{TiO}_{2}$ for dye-sensitized solar cell applications. Spectrochimica Acta Part A: Molecular and Biomolecular Spectroscopy, 138(205), 130137.

Bethouex, P. M., \& Brown, L. F. (1994). Statistics for environmental engineers (1st ed.) Boca Raton: Lewis Publishers.

Borras-Linares, I., Fernandez-Arroyo, S., Arraez-Roman, D., Palmeros-Suarez, P. A., Del Val-Diaz, R., Andrade-Gonzales, I., et al. (2015). Characterization of phenolic compounds, anthocyanidin, antioxidant and antimicrobial activity of 25 varieties of Mexican Roselle (Hibiscus sabdariffa). Industrial Crops and Products, 69, 385-394.

Cabrera, M., Fiqueroa, J. G., Ramirez-Perez, J. C., \& Solano-Cueva, N. (2017). Celdas solares sensibilizadas con colorantes fotosensibles obtenidos de plantas de la región sur del Ecuador. Química Nova, 40(3), 260-263.

Calogero, G., Bartolotta, A., Di Marco, G., DiCarlo, A., \& Bonaccorso, F. (2015). Vegetable-based dye-sensitized solar cells. Chemical Society Reviews, 44, 3244-3294.

Calogero, G., Yum, J.-H., Sinpoli, A., Di Marco, G., Gratzel, M., \& Nazeerrudin, M. K. (2012). Anthocyanins and betalians as light-harvesting pigments for dyesensitized solar cells. Solar Energy, 86, 1563-1575.

Chang, H., \& Lo, Y. J. (2010). Pomegranate leaves and mulberry fruit as natural sensitizers for dye-sensitized solar cells. Solar Energy, 84, 1833-1837.

Cherepy, N. J. G. P., Smestad, M., Gratzel, M., \& Zhang, J. Z. (1997). Ultrafast electron injection: Implication for a photoelectrochemical cell utilizing an anthocyanin dye-sensitized $\mathrm{TiO}_{2}$ nanocrystalline electrode. The Journal of Physical Chemistry B, 101, 9342-9351. 
Coba, P., Coronel, D., Verdugo, K., Paredes, M., Yugsi, E., \& Huachi, L. (2012). Estudio etnobotanico del Mortiño (Vaccinium floribundum) como alimento ancestral y potencial alimento functional. Review La Granja, Universidad Politécnica Saleciana, Quito, Ecuador.

Costa-Rocha, I. D., Bonnlaender, B., Sievers, H., Pischel, I., \& Heinrich, M. (2014). Hibiscus sabdariffa L.-A photochemical and pharmacological review. Food Chemistry, 165, 424-443.

Georgescu, A., Damache, G., \& Girtu, M. A. (2008). Class A small area solar simulator for dye-sensitized solar cell testing. Journal of Optoelectronics and Advanced Materials, 10, 303-307.

Gokilmeni, N., Mathukumarasamy, N., Thambidurai, M., Ranjitha, A., Velauthapillai, D., Senthil, T. S., et al. (2013). Dye sensitized solar cells with natural extracted from rose petals. Journal of Materials Science: Materials in Electronics, 24, 3394-3402.

Hernandez-Martinez, A. R., Vargas, S., Estevez, M., Rodriguez, M. (2012). Natural pigment based dye-sensitized solar cells. In: 1st International congress on instrumentation and applied sciences (Vol. 10, pp. 1-15).

Holgren, N. H., \& Holmgren, P. K. (2005). Vascular plants of the intermountain west, USA, subclass Dilenidae. Intermount, 2(b), 1-488.

Idarraga-Piedrahita, A., Ortiz, R., Callejas, P., \& Merello, M. (2011). Flora de Antioquia. Catalogo de las Plantas Vasculares, 2, 1-939.

International Union for the Protection of New Varieties of Plants (UPOV). (2000). Report 34th ordinary session, Geneva, October 26, 2000.

Kim, S.-S., Na, S.-I., Jo, J., Kim, D.-Y., \& Nah, Y.-C. (2008). Plasmon enhanced performance or organic solar cells using electrodeposited Ag nanoparticles. Applied Physics Letters, 93, 1-3.

Kohraku, S., \& Kurokawa, K. (2003). New methods for solar cells measurement by led solar simulator. Photovoltaic Energy Conversion, 2, 1977-1980.

Lee, J. W., Kim, T. Y., Ko, H. S., Han, S., \& Lee, S.-H. (2015). Influence of polar solvents on photovoltaic performance of Monascus red dye-sensitized solar cell. Spectrochimica Acta Part A:Molecular and Biomolecular Spectroscopy, 126, 76-80.

Lim, A., Damit, D.-N. F. B., \& Ekanayak, P. (2015). Tailoring of extraction solvent of Ixora coccinea flower to enhance charge transport properties in dye-sensitized solar cells. Ionics, 21, 2897-2904.

Ludin, N. A., Mahmoud, A. A. A., Mohamad, A. B., Kadhum, A. A. H., Sopian, K., \& Karim, N. S. A. (2014). Review on the development of natural dye photosensitizer for dye-sensitized solar cells. Renewable and Sustainable Energy Reviews, 31, 386-396.

Mozaffari, S. A., Saedi, M., \& Rahmanian, R. (2015). Photoelectric characterization of fabricated dye-sensitized solar cells using dye extracted from red siahkooti fruit as natural sensitizer. Spectrochimica Acta Part A:Molecular and Biomolecular Spectroscopy, 142, 226-231.

Nayaran, M. R. (2012). Review: Dyes sensitized solar cells based on natural photosensitizers. Renewable and Sustainable Energy Reviews, 16, 208-215.

Polo, A. S., \& Iha, N. Y. M. (2006). Blue sensitizers for solar cells: Natural dyes from Caafate and Jaboticaba. Solar Energy Materials \& Solar Cellls, 90, 1936-1944.
Ramirez-Perez, J. C., \& Solano, N. (2013). Dye-sensitized solar cell using vegetable dyes from Ecuador. In Proceedings of the 1st international conference sustainable renewable energy research and energy efficiency, Quito-Ecuador (Vol. 1, pp. 28-29).

Ranner, S., Baslev, H., \& Holm, L. B. (1990). Flowering plants of Amazonia Ecuador-A check list. AAU REP, 24, 1-241.

Salam, Z., Vijayakumar, E., Subramania, A., Sivasankar, N., \& Sudhanshu, M. (2015). Graphene quantum dots decorated electrospum $\mathrm{TiO}_{2}$ nanofibers as an effective photoanode for DSSCs. Solar Energy Materials and Solar Cells, 143, 250-259.

Sarli, A. (1980). Tratado de Horticultura, Buenos Aires (argentina). Hemisferio Sur. ISBN 950-504-144-6.

Shalini, S., Balasundara, R., Peasanna, S., Mallick, T. K., \& Senthilarasu, S. (2015). Review on natural dye sensitized solar cells: operation, materials and methods. Renewable and Sustainable Energy Reviews, 51, 1306-1325.

Snaith, H. J. (2010). Estimating the maximum attainable efficiency in dye-sensitized solar cells. Advanced Functional Materials, 20, 13-19.

Sreekala, C. O., Jinchu, I., Sreelatha, K. S., Janu, Y., Prassad, N., Kumar, M., et al. (2012). Influence of solvents and surface treatment on photovoltaic response of DSSC based on natural curcumin dye. IEEE Journal of Photovoltaics, 2, 312-319.

Suhaimi, S., Shahimin, M. M., Alahmed, Z. A., Chysky, J., \& Reshak, A. H. (2015). Materials for enhanced dyes-sensitized solar cells performance: electrochemical application. International Journal of Electrochemical Science, 10, 2859-2871.

Sunk Jung, H., \& Lee, J.-K. (2013). Dye sensitized solar cells for economically viable photovoltaic systems. The Journal of Physical Chemistry Letters, 4, 1682-1693.

Tekerek, S., Kudret, A., \& Alver, U. (2011). Dye-sensitized solar cells fabricated with black raspberry, black carrot and rosella juice. Indian Journal of Physics, 85, 1469-1476.

Vekariya, R. L., Sonogara, K. K., Fadadu, K. B., Vaghasiya, J. V., \& Soni, S. S. (2016). Humic acid as a sensitizer in highly stable dye solar cells: Energy from an abundant natural polymer soil component. ACS Omega, 1, 14-18.

Warkkoyo, E. A. S. (2011). The solvent effectiveness on extraction process of seaweed pigment. Makara Teknologi, 15, 5-8.

Wongcharee, K., Meeyo, V., \& Chavadej, S. (2007). Dye-sensitized solar cells using natural dyes extracted from rosella and blue pea flowers. Solar Energy Materials and Solar Cells, 91, 566-571.

Zhou, H., Wu, L., Gao, Y., \& Ma, T. (2011). Dye-sensitized solar cells using 20 natural dyes as sensitizers. Journal of Photochemistry and Photobiology A:Chemistry, 219, 188-194.

Zuloaga, F. O., Morrone, M. J., Belgrano, J., \& Marticorena, C. (2008). Catalogo de las plantas vasculares del Cono Sur. Missouri Botanical Garden, 107(1-3), 1-3348.

\section{Publisher's Note}

Springer Nature remains neutral with regard to jurisdictional claims in published maps and institutional affiliations.

\section{Submit your manuscript to a SpringerOpen ${ }^{\circ}$ journal and benefit from:}

- Convenient online submission

- Rigorous peer review

- Open access: articles freely available online

- High visibility within the field

- Retaining the copyright to your article

Submit your next manuscript at $\boldsymbol{\nabla}$ springeropen.com 